\title{
Redes sociais de produtores de mandioca em regiões do estado de São Paulo
}

Social networks of cassava farmers in regions of São Paulo state

\section{Les réseaux sociaux de producteurs de manioc dans lens régions de São Paulo}

Las redes sociales de los productores de yuca en regiones de São Paulo

\author{
Giuliana Aparecida Santini Pigatto* \\ (giusantini@tupa.unesp.br) \\ Timóteo Ramos Queiroz* \\ (timoteo@tupa.unesp.br)
}
Ana Elisa Bressan Smith Lourenzani*
(anaelisa@tupa.unesp.br)

Recebido em 17/02/2014; revisado e aprovado em 15/07/2014; aceito em 23/08/2014

DOI: http:/ /dx.doi.org/10.1590/1518-70122015106

\begin{abstract}
Resumo: Este artigo analisou e mapeou as redes sociais entre produtores de mandioca no estado de São Paulo, formadas na busca de informação acerca da produção e comercialização. Foi utilizada uma pesquisa descritiva, utilizando questionários semiestruturados, em Tupã e Assis. O software UCINET auxiliou na análise das interações nas redes. Os resultados indicam que, em Tupã, a rede é difusa e há pouca interação com instituições de transferência tecnológica. Em Assis, as redes são coesas com maior difusão tecnológica.

Palavras-chave: Redes sociais. Comercialização. Mandioca.

Abstract: This paper analyzed and mapped social networks among cassava farmers in São Paulo, gathered in search of information regarding production and marketing. A descriptive research, using semi-structured questionnaires, in Tupa and Assis regions, was conducted. UCINET software assisted the analysis of interactions within networks. The results indicate that Tupa network is diffuse and there is little interaction with technology transfer institutions. In Assis, the network is cohesive with greater technological diffusion.

Key words: Social networks. Commercialization. Cassava.

Résumé: Cet étud analysé et conçu les réseaux sociaux entre les producteurs de manioc dans l'état de São Paulo, formé à la recherche d'informations sur la production et la commercialisation. Une étude descriptive a été utilisée, en utilisant des questionnaires semi-structurés, à Tupa et Assise. Le logiciel UCINET aidé à l'analyse des interactions dans des réseaux. Les résultats indiquent que Tupa dans le réseau est diffus et il ya peu d'interaction avec les institutions de transfert de technologie. A Assise, les réseaux sont cohérent avec une plus grande diffusion de la technologie.

Mots-clés: Réseaux sociaux. Commercialization. Manioc.

Resumen: En este trabajo se analiza las redes sociales entre los productores de yuca en São Paulo, que se formó en la búsqueda de información sobre la producción y comercialización. Se utilizó un estudio descriptivo, utilizando cuestionarios semi estructurados, en Tupa y Assis. UCINET ayudo en el análisis de las interacciones en las redes. Como resultados en Tupa redes son difusas y hay poca interacción con instituciones de transferencia de tecnología. En Assis, las redes son cohesivas con mayor difusión tecnológica.

Palabras-clave: Redes sociales. Comercialización. Yuca.
\end{abstract}

\section{Introdução}

Dentre as diversas análises de setores industriais, segmentos produtivos ou grupos de empresas, destacam-se aquelas que realizam abordagem de caráter econômico e/ou de eficiência produtiva. Essas formas de análises, explicadas talvez pela mais fácil interpretação dos dados ou pelo contingente de autores que as tomam como rotina, são preponderantes nas interpretações das diversas realidades (WILLIAMSON, 1975, 1996), porém não são suficientes para explicar certos comportamentos de grupos de agentes, sucesso coletivo ou comportamentos semelhantes entre segmentos produtivos de setores específicos.

As análises no âmbito de um contexto econômico não deveriam ser realizadas com um foco impessoal, ou seja, com uma abordagem desconectada das interações sociais. Isso porque as redes de relações entre os agentes afetam o comportamento econômico, fazendo com que as relações sociais sejam tão importantes quanto as de ordem econômica (SIEGEL, 2009; GRANOVETTER, 2007; 1973). Assim, a análise das Redes Sociais ou Social Network Analysis (SNA) compreendem

* Universidade Estadual Paulista (UNESP), Campus Tupã, São Paulo, Brasil. 
uma variedade de ferramentas e disciplinas acadêmicas, que de modo integrado são amplamente utilizadas para estudos de redes sociais entre indivíduos, empresas e quaisquer agentes econômicos que pratiquem algum tipo de interação social ou econômica (HENNEBERG et al., 2009). Alguns trabalhos na área internacional podem ser citados com o uso da abordagem de redes sociais, como por Crespo, Requier-Desjardins e Vicente (2014), para o enfoque de sistemas de produção alimentar local; Senghore et al. (2014), para o enfoque de redes de inovação a programa vinculado à NASA; Worrell, Wasko e Jonston (2014) em pesquisas de sistema de informação contábeis; Mertens, Saint-Charles e Mergler (2012), em pesquisa participativa visando à adoção de novos comportamentos de consumo.

De modo geral, a SNA pode ser definida como um modo estrutural de análise das inter-relações de grupos, proporcionando um sistema de acesso às informações das redes, por meio do mapeamento e análise das relações existentes entre pessoas, grupos, departamentos ou, até mesmo, organizações como um todo (HENNEBERG et al., 2009; CROSS; BORGATTI; PARKER, 2002).

A abordagem de redes contrapõe, ou melhor dizendo, complementa os estudos focados unicamente nas abordagens econômicas e de eficiência produtiva, podendo ser trabalhada em conjunto com outras técnicas de análises. Esse tipo de abordagem amplia a possibilidade de explicação do funcionamento de setores específicos, como o agronegócio, ou ainda mais delimitado, da produção da mandiocultura (segmento de estudo em questão).

Quando analisadas as configurações em rede, um aspecto a ser considerado é o da coesão em que a rede está configurada. $\mathrm{Na}$ definição de Schaefer e Kornienko (2009), a coesão de uma rede pode ser entendida como o senso de proximidade, comprometimento e harmonia que os relacionamentos das redes proporcionam. A materialização dessas relações positivas (coesas) poderia e, na maioria dos casos se confirma, gerar benefícios para os componentes da rede, a exemplo de agentes que conseguem ter melhores acessos às informações de mercado, adotam tecnologias e processos mais adequados e, até mesmo, maiores vantagens na comercialização dos produtos. A coesão das redes melhora a transmissão das informações, evitando lacunas ou desconexões dos agentes, os chamados buracos estruturais ${ }^{1}$. Também para Ahuja (2000), vários estudos têm indicado que as posições dos agentes em redes interorganizacionais podem influenciar o comportamento dos mesmos e seus resultados.

Para Ahuja, Soda e Zaheer (2012), a arquitetura de uma rede pode ser conceituada em termos de três fatores, como os nós que compõem a rede (número, identidade e características de nós), os laços que ligam esses nós (localização, conteúdo ou a força) e os padrões ou estruturas que resultam dessas ligações. $\mathrm{O}$ grau de distribuição de nós reflete a frequência relativa de ocorrência de laços entre nós ou a variação na distribuição de laços na rede. A rede pode apresentar alguns nós que são caracterizados por muitas ligações (comparativamente a outros nós), enquanto muitos outros nós podem apresentar menor número de laços. Alternativamente, os laços em uma rede podem ser mais bem distribuídos entre os nós, sendo que esse grau de distribuição tem sido usado para significar a distribuição de status, poder ou prestígio entre as organizações (AHUJA; POLIDORO JR.; MITCHELL, 2009; AHUJA; SODA; ZAHEER, 2012).

Para Ahuja, Soda e Zaheer (2012), a conectividade de rede pode ser avaliada no diâmetro de uma rede, que por sua vez reflete a maior distância entre quaisquer dois nós da rede. De modo geral, o comprimento médio do percurso de ligação de quaisquer dois nós da rede é um indicador da ligação. No contexto de uma rede de organização, a proximidade dos agentes em rede permite que informações possam ser difundidas mais rapidamente, promovendo-se inovação e criatividades.

Desse modo, dentre as vantagens apontadas pela coesão e proximidade dos agentes em rede está a transferência de conhecimentos (knowledge transfer), potencializada principalmente pela coesão da rede. De acordo com Reagans e McEvily (2003), a transferência de conhecimentos - compreendido no presente estudo como a rede de informações entre os produtores de mandioca e agentes/

\footnotetext{
${ }^{1}$ Para Burt (1997), buracos estruturais, ou structural holes, são compreendidos como lacunas do fluxo de informações entre grupos de indivíduos interconectados.
} 
instituições de apoio - é primeiramente potencializada pela boa vontade dos indivíduos em dedicar esforços para prestar assistência aos demais, favorecendo os processos de reciprocidade e confiança entre os envolvidos nas redes. Para Reagans e McEvily (2003), o fato de haver uma melhoria da troca de informações, consolidando uma transferência de conhecimento, reforça o processo de redes como mais profícuo do que a simples busca de informações por meio de agentes externos à rede, com relações não frequentes e isoladas. Assim, o principal objetivo deste trabalho é o de analisar e mapear as redes sociais entre produtores de mandioca no estado de São Paulo - especificamente, regiões de Tupã e Assis - e agentes/instituições correlacionadas, relacionando-as à busca de informação para tomada de decisão no que diz respeito à produção e comercialização, por meio de uma comparação entre as duas regiões produtoras. O Brasil é o principal produtor de mandioca, no âmbito das Américas (23,4 milhões de toneladas em 2012), respondendo por $72 \%$ da produção na América do Sul e 9,2\% da produção mundial do ano de 2012, ocupando a terceira posição no ranking mundial, atrás somente da Nigéria e Indonésia (FAO, 2013). O estado de São Paulo é o sexto maior produtor brasileiro e maior produtor da região Sudeste, e vem apresentando aumentos importantes, principalmente da mandioca para indústria, que apresentou no período de 2000 a 2012, um crescimento de $52 \%$ na produção; a área de produção também variou, mas expressando crescimento de $12 \%$ no período (IEA, 2013).

Por meio da SNA, este estudo contribui para visualização e interpretação de diferentes formatos de compartilhamento e difusão de informação entre os grupos de produtores, instituições e organizações, ampliando o envolvimento de atores públicos e privados para o melhor aproveitamento de fluxo de informação.

O artigo está organizado em cinco seções. Nesta primeira seção, são discutidas as contribuições de redes sociais e os objetivos propostos; na segunda seção é caracterizada sucintamente a mandiocultura; na terceira seção, estão descritos os métodos e procedimentos adotados; na quarta seção, são realizadas as análises propostas, alcançando-se as considerações finais, na quinta seção.

\section{Atividade da mandiocultura}

A mandioca é uma raiz rica em substâncias nutritivas, originária do Brasil e presente na maioria dos países tropicais. $\mathrm{O}$ produto serve como alimento energético para aproximadamente 500 milhões de pessoas, principalmente nos países em desenvolvimento (AGRIANUAL, 2010; CARDOSO, 2003). Os produtos gerados a partir da cultura têm como destino o consumo in natura ou industrializado. Para Camargo Filho e Alves (2004), o consumo in natura serve como base para alimentação humana ou animal. Porém é no consumo para a indústria que a cultura merece destaque, dada a diversidade de uso - indústrias alimentícias, farmacêutica, têxtil, de papel e adesivos, madeireira e, também, de biocombustível - com ampla variedade de derivados, destacando-se: farinha, amido (fécula), amido fermentado (polvilho doce ou azedo), raspas, álcool, além de outros (HOWELER; LUTALADIO; THOMAS, 2013).

Em âmbito mundial, a produção total dessa cultura foi de 256,5 milhões de toneladas, considerando o ano de 2012 (FAO, 2013), com expansão de $45,5 \%$ no período 2000 a 2012, impulsionada pela demanda da Ásia e África. Os países africanos, entre os quais o principal produtor é a Nigéria, são os maiores produtores mundiais, representando $57 \%$ e utilizam a mandioca como cultura de subsistência, gerando alimento e renda para a população (FUKUDA; OTSUBO, 2003). Nos países asiáticos (destaca-se a Indonésia), segundo maior produtor, e também no Brasil, terceiro maior produtor, a produção é voltada principalmente para a industrialização, sendo os produtos mais representativos no Brasil, a farinha e a fécula².

A produção no Brasil é observada em todo o território nacional, devido à sua alta adaptabilidade, por não necessitar de cuidados específicos como outras culturas. $\mathrm{O}$ armazenamento, por exemplo, pode ocorrer no próprio solo, até o momento adequado de colheita. Na questão econômica, a cultura advém como fonte geradora de renda, tanto

\footnotetext{
${ }^{2}$ A farinha possui uso essencialmente alimentar e a fécula, podendo ser usada na alimentação humana ou como insumos em diversos setores da indústria, como: embutidos, embalagens, colas, mineração, têxtil e farmacêutica (CARDOSO, 2003a; CEREDA, 2002).
} 
para os produtores como para o país, bem como na participação da alimentação dos produtores e demais consumidores do sistema produtivo. Segundo Cardoso e Gameiro (2003), considerando-se a fase de produção primária e o processamento de farinha e de fécula, estima-se que são gerados no Brasil um milhão de empregos diretos no agronegócio.

As regiões que detêm destaque na produção no Brasil são Nordeste e Norte, sendo a produção, nessas regiões, voltada para alimentação humana, na forma de farinha. Já na região Sul e Sudeste, grande parte da produção é destinada para a indústria, principalmente nos estados do Paraná, São Paulo, Santa Catarina e Minas Gerais (CARDOSO; GAMEIRO, 2003).

Considerando a propriedade rural, a produção da mandioca no país estaria distribuída entre a unidade doméstica, a unidade familiar e a unidade empresarial. A unidade doméstica, segundo Barros (2004), é caracterizada por usar mão de obra familiar, não utilizar tecnologias modernas, pouco participar do mercado e dispor de capital de exploração de baixa intensidade. Já a unidade familiar, ao contrário da unidade doméstica, já adota algumas tecnologias modernas, possui uma participação significativa no mercado e dispõe de capital de exploração em nível mais elevado que a unidade anterior. A contratação de mão de obra de terceiros é a característica marcante da unidade empresarial, além do nível tecnológico e intensidade no uso de capital ser expressivo. A unidade empresarial, junto com a do tipo familiar, responderia pela maior parte da produção de raízes, segundo Barros (2004) ${ }^{3}$.

Segundo Howeler, Lutaladio e Thomas (2013), na produção de países da América Latina e Caribe, tem havido uma mudança significativa, desde a década de 1990, em direção à maior escala, principalmente de produção mais intensiva no Brasil. Assim, a análise de redes com foco no Brasil, especificamente o contexto de duas regiões do estado São Paulo, vem contribuir para o diagnóstico em torno de busca de informação de produtores que tenham um perfil de maior produção, voltada principalmente à industrialização.

\footnotetext{
${ }^{3}$ Na produção de mandioca de mesa há predominância da unidade familiar, enquanto na cadeia da mandioca para indústria, predomina as unidades familiares e empresariais (BARROS, 2004).
}

Apesar de a mandioca ser adaptável aos diversos tipos de clima, solo e ambiente, o estado de São Paulo apresenta diversas características favoráveis para a produção da planta, em termos de clima e solo. Este último, apesar de heterogêneo, é adequado em sua maioria, além disso, a utilização de múltiplas variedades de mandioca contribui para o sucesso desta no Estado. De todas as regiões do estado, os Escritórios de Desenvolvimento Regional (EDR) de Assis, Ourinhos, Mogi-Mirim, Tupã e Presidente Prudente foram os mais representativos na produção no triênio 2010-2012, somando juntos, aproximadamente $77 \%$ da produção do estado em relação à média do triênio. Desses, alguns também foram expressivos no aumento de produção e de área plantada no período de 2000 a 2012, com destaque para a região de Assis (maior região produtora do estado) e de Tupã (IEA, 2013). Vale comentar que essas duas regiões também tiveram incremento de agentes produtores, sendo que, no período 1995/1996, as regiões de Assis e Tupã possuíam 666 e 68 , respectivamente, unidades de produção com mandioca; no período de 2007/2008, esses números passaram a 819 e 179 , respectivamente. Ou seja, um incremento muito expressivo, de $163 \%$ para a região de Tupã, comparativamente ao da região de Assis, 22,9\% (LUPA, 1996; 2008).

\section{Metodologia}

Este trabalho é resultante de uma pesquisa de natureza qualitativa, que envolveu busca e análise de informações da atividade relacionada à mandiocultura no Brasil e no estado de São Paulo, bem como a realização de levantamento bibliográfico acerca da abordagem de Redes Sociais - suporte à pesquisa. Os métodos qualitativos apresentam uma mistura de procedimentos de cunho racional e intuitivo, capazes de contribuir para a melhor compreensão dos fenômenos e interpretação dos aspectos profundos do comportamento humano, do que em sua mensuração, ao contrário dos métodos quantitativos, que se preocupam com a medida dos fenômenos e que utilizam geralmente amostras amplas e informações numéricas (MARCONI; LAKATOS, 2003).

A pesquisa também possui caráter descritivo, cujo objetivo foi o de conhecer e 
interpretar a realidade, sem a intenção de interferir para modificá-la. Nesse sentido, a descrição auxiliou no alcance do objetivo do trabalho, por meio da compreensão do processo de busca de informações dos produtores no tocante ao planejamento de produção e comercialização (neste caso, contribuindo inclusive, ao entendimento dos fatores motivadores de entrada na atividade). Segundo Gil (2002), a pesquisa descritiva tem como objetivo primordial a descrição das características de determinada população ou fenômeno, ou então, o estabelecimento de relações entre as variáveis. Em se tratando dos procedimentos técnicos da pesquisa e por abordar uma pesquisa descritiva qualitativa, foi necessário estabelecer um método adequado de investigação, sendo utilizado o de pesquisa de campo. Os estudos de campo procuram $\mathrm{o}$ aprofundamento das questões propostas, $\mathrm{e}$ seu planejamento possui maior flexibilidade, podendo ocorrer mesmo que seus objetivos sejam reformulados ao longo do processo de pesquisa, além disso, o pesquisador realiza maior parte do trabalho pessoalmente, para ter uma experiência direta com a situação (GIL, 2002).

Para a pesquisa de campo com os agentes produtores, foi utilizado um processo de amostragem não probabilístico. Segundo Marconi e Lakatos (2003), a amostragem é utilizada quando não há a possibilidade de pesquisar todos os indivíduos do grupo que se deseja estudar, devido à escassez de recursos ou a premência do tempo. Assim, consiste em obter um juízo sobre o total, mediante a compilação e exame de apenas uma parte, a amostra, selecionada por procedimentos científicos. A partir de dados obtidos no Levantamento das Unidades de Produção Agropecuária - LUPA ${ }^{4}$ (2007/2008), observou-se o número de unidades de produção de mandioca tipo indústria nas regiões de Tupã (179) e de Assis (819). Contatos foram realizados com as CATIs dos municípios de Tupã e Assis, e as Secretarias de Agricultura dos municípios das regiões para a obtenção de nomes e contatos dos produtores. A listagem de produtores fornecida por esses órgãos

\footnotetext{
${ }^{4}$ Levantamento das Unidades de Produção Agropecuária, realizado a cada dez anos pela Secretaria de Agricultura do Estado de São Paulo.
}

constava aproximadamente de 60 produtores efetivos para os municípios da região de Tupã e aproximadamente 100 para os municípios da região de Assis. Com posse dessa listagem, foi realizado contato telefônico para agendamento das entrevistas; 28 produtores para a região de Tupã e 31 para a região de Assis se dispuseram a colaborar com a pesquisa.

Questionários semiestruturados foram então aplicados a 59 produtores ${ }^{5}$. As entrevistas foram realizadas in loco, durante os anos de 2011 e 2012, de acordo com a disponibilidade dos produtores em repassar as informações.

As principais questões analisadas foram relacionadas aos fatores motivadores de entrada, ao planejamento para a tomada de decisão de produção, busca de informação relacionada a este planejamento e à comercialização, tomando-se como base, um levantamento bibliográfico (prévio) realizado em torno da cultura da mandioca.

Para o mapeamento da busca de informação para a tomada de decisão de produção e comercialização, foi utilizada como ferramenta o software UCINET, conforme descrito por Borgatti, Everett e Freeman (2002), auxiliando na análise e descrição das interações dos produtores e agentes externos. Foi adotado o método de Social Network Analysis (SNA), que atendesse às características da pesquisa, principalmente no âmbito da análise e interpretação das interações entre agentes que configuram uma rede (HENNEBERG et al., 2009).

\section{Fatores motivadores de entrada e a busca de informações para aspectos de produção e comercialização}

Do ponto de vista comercial, foi identificado se variáveis relacionadas a preços, facilidade de venda/ escoamento do produto, possibilidade de rotação de cultura, risco financeiro reduzido, facilidade de produção e outros favoreceram a entrada na atividade

\footnotetext{
${ }^{5}$ Também foram realizados workshops com os produtores nos municípios de Tupã e de Assis, previamente à pesquisa de campo, com o apoio da Coordenadoria de Assistência Técnica e Integral do estado de São Paulo, secretarias de agricultura e órgãos relacionados, com o objetivo de sensibilizá-los a respeito do objetivo da pesquisa e dos procedimentos que a partir de então seriam realizados, como a aplicação de questionários.
} 
da mandiocultura. Esses fatores são importantes no processo de comercialização, uma vez que este compreende um conjunto amplo de decisões a ser pensado já no momento em que o produtor decide o que produzir, como produzir, quanto produzir e para quem produzir (MENDES; PADILHA JR., 2007).

Como resultado pôde-se notar motivos/incentivos de entrada diferentes para produtores das regiões de Assis e Tupã, sendo os mais expressivos, a rotação de cultura ${ }^{6}$ (32\% dos entrevistados para a região de Assis) e a variável preço ( $25 \%$ dos entrevistados para a região de Tupã). Além desses fatores, outros, como a tradição na região e a presença de fecularias e farinheiras, também contribuíram para o aumento de novos entrantes.

Para os produtores da região de Tupã, o aumento dos preços, principalmente no ano de 2004, foi um importante indutor do crescimento no número de produtores de mandioca, atrelado à abertura de uma empresa de fecularia na região ${ }^{7}$. Em trabalho complementar a respeito da cultura, Santini, Oliveira e Pigatto (2010) constatam que, de toda a série histórica de preços da mandioca tipo indústria para o estado (dados de 1996 a 2008), houve um ciclo de preço de maior significância, oriundo de variações cíclicas na oferta, nos limites aproximados de novembro de 2002 a maio de 2006. Das 156 observações consideradas, o maior preço observado foi de US\$42,16/ ton $^{8}$, referente ao mês de Março/2004. Este fator atraiu diversos produtores, porém, com o aumento da oferta da raiz, o preço médio por tonelada caiu expressivamente em menos de três anos posteriores. Os menores produtores não conseguiram se manter após a baixa dos preços e saíram da atividade, restando apenas quem possuía maior aporte financeiro para investir e não abandonou o cultivo de outras culturas, como amendoim e gado.

Ao abordar o incentivo à entrada, também foi averiguado o planejamento dos produtores para o início das atividades, especificamente as variáveis "como produzir, quanto, como e onde vender, preços que poderia receber", conforme Mendes e Padilha Jr. (2007). Para a amostra analisada da região de Assis, $80 \%$ dos entrevistados responderam haver buscado informações para realização de planejamento da atividade.

Referente aos produtores da região de Tupã, apenas $50 \%$ dos entrevistados disseram realizar algum tipo de planejamento ou buscaram informações específicas. À priori, para a maior parte dos agentes já havia a informação (comercial) disseminada, como de 'a quem vender' na região e 'preços', em termos de fecularia ou farinheira; uma informação crucial a ser buscada seria, também, a de como realizar a produção.

Os produtores da amostra da região de Tupã podem ser classificados como de ingresso recente na produção (todos os entrevistados com menos de 20 anos de atividades, com maior frequência - $64 \%$ - na faixa de até 10 anos), quando comparados com a amostra de produtores da região de Assis $(22,5 \%$ dos produtores apresentam mais de 20 anos de atividades, com concentração na faixa entre 10,1 a 20 anos - 42\%). Tal característica histórica e de formação do grupo de produtores (amostra) da região de Tupã pode, conforme reforçado pelas teorias da SNA, ser uma das explicações da forma como os produtores se relacionam e buscam informações sobre as questões produtivas. A Figura 1 apresenta o mapeamento da rede de busca de informações para produtores da região de Tupã.

\footnotetext{
${ }^{6}$ Utilização da mesma área para produção de mandioca e outras culturas, como grão e cana de açúcar, em diferentes períodos.

${ }^{7}$ Entrada medida em anos, dentre os intervalos menor de 10 anos, de 10,1 a 20 anos e maior de 20,1 anos, sendo constatada para a amostra de Tupã, mais expressiva entrada há menos de 10 anos (2002 a 2011).

${ }^{8} \mathrm{O}$ preço em moeda brasileira (reais) foi de $\mathrm{R} \$ 122,27$, deflacionado com índice geral de preços-disponibilidade interna e base maio 1996. Para a conversão em moeda norte-americana foi utilizada uma taxa de câmbio (média mensal) de R\$2,9/US\$ de março de 2004.
} 


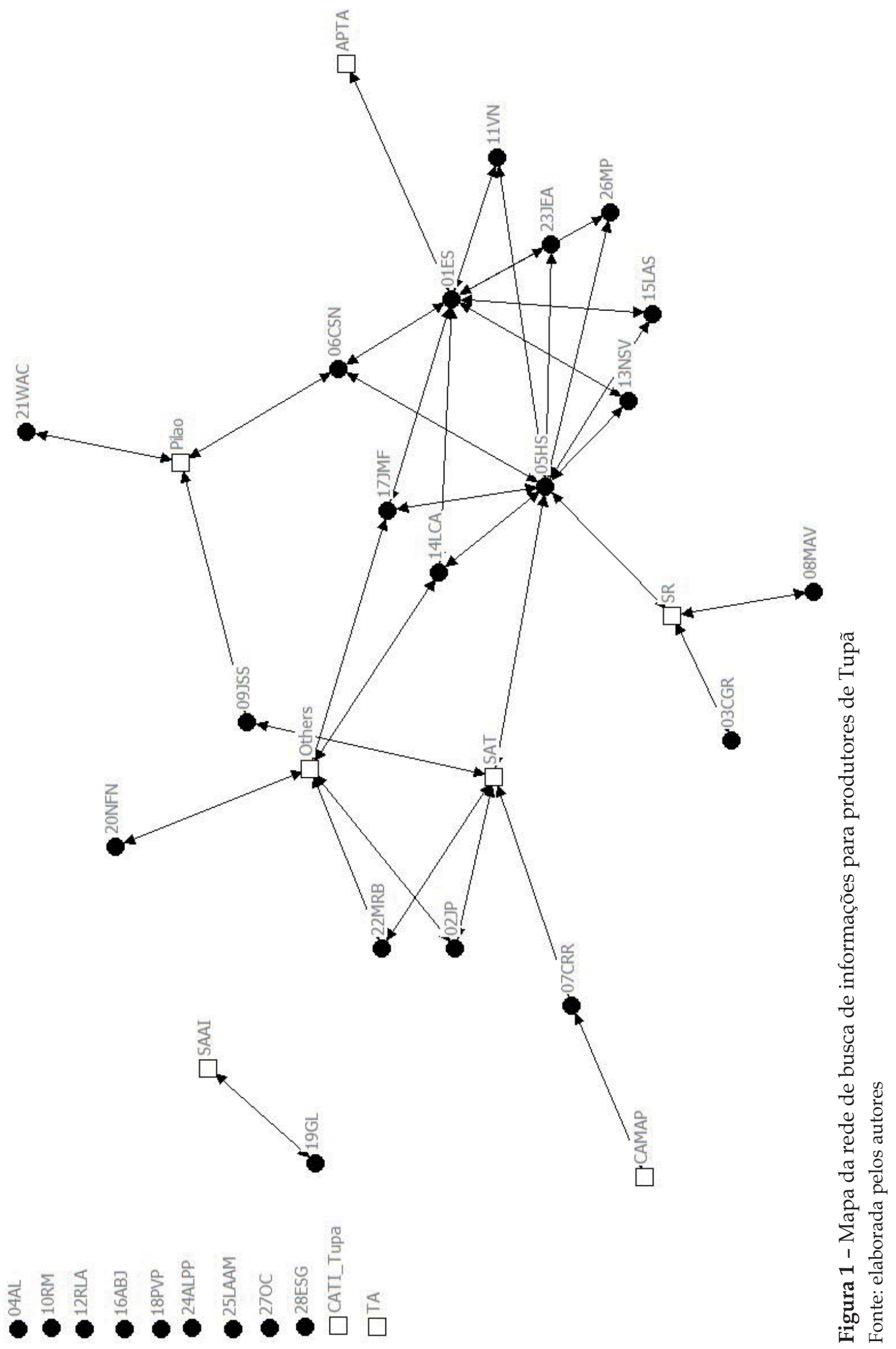


Na rede de Tupã, é possível verificar a participação de sete nós (agentes) que não são produtores, mas servem como intermediários das informações (principalmente para tomada de decisão da produção), tais como Secretaria Municipal de Agricultura de Tupã (SAT), Pesquisador ligado à Agência Paulista de Tecnologia dos Agronegócios (APTA), Sindicato Rural de Tupã (SR), empresa Pilão Amidos (Pilao) ${ }^{9}$, Cooperativa Agrícola Mista da Alta Paulista (CAMAP), Secretaria Municipal de Agricultura de Arco Íris (SAAI), além de outras fontes de informação (Outras). Esses nós cumprem o papel de 'pontes ${ }^{10}$ de informação, uma vez que se caracterizam por agentes (não produtores) públicos e de interesse privado que fornecem assistência técnica ou informações para produção. Na possível ausência destes, haveria buracos estruturais e isolamento de alguns agentes produtores. A importância desses nós não produtores, servindo de pontes, pode ser medida pelo número de laços que sustentam, sendo os mais importantes: a Secretaria Municipal de Agricultura de Tupã (SAT), outras fontes (como cursos, palestras e literatura impressa e eletrônica), agente comprador (Pilao) e órgão de classe (SR).

Outros agentes, como a Coordenadoria de Assistência Técnica Integral - Escritório de Desenvolvimento Rural de Tupã (CATI_ Tupã) e Assistência Técnica Privada (AT) estiveram listados no questionário, porém não foi verificada nenhuma ligação com os produtores, pelo motivo de estarem isolados da rede, ou seja não formam laços ${ }^{11}$. Para melhor compreensão e visualização, na montagem do mapa, foram utilizadas as abreviaturas, constantes em parênteses.

Ainda em relação à rede de informações dos produtores da amostra de Tupã, nota-se a presença de nove produtores $(32,1 \%)$ à esquerda do mapa, de um total de 28 analisados, que alegam não buscar informações em nenhuma fonte, não constituindo laços com o restante da rede. Características importantes que auxiliam na compreensão desse perfil é o fato de $50 \%$ destes utilizarem a terra na forma de arrendamento e também terem menor

\footnotetext{
${ }^{9}$ A troca de informação com esse agente é mais específica para fatores comerciais.

${ }^{10} \mathrm{O}$ termo originalmente adotado foi bridge, conforme Granovetter (1973).

${ }^{11} \mathrm{O}$ instrumento de coleta não contemplou os motivos desse resultado.
}

tempo de ingresso na atividade ( $75 \%$ até 10 anos na atividade), o que poderia levar a um menor tempo de estreitamento de laços entre os pares (principalmente), comparativamente a produtores que já possuem tempo acima de 10 anos. Esse comportamento, em geral, faz com que o produtor não se beneficie da troca de informações sobre questões produtivas, de comercialização, riscos e potencialidades do mercado.

Dos outros 19 produtores $(67,9 \%)$, pôdese constatar que um grupo de produtores buscou informações de produção (principalmente) e comercialização na Secretaria de Agricultura do município de Tupã (SAT), de modo predominante. Desse modo, esse nó não produtor passa a cumprir um papel relevante na fluidez e difusão de informações comerciais e de produção nesse grupo. Destaca-se que este é um órgão público cujo papel é fomentar as atividades agropecuárias do município. No outro grupo, o principal meio de transmissão da informação foi por meio de outros produtores (produtores números 01ES e 05HS), conforme pode ser verificado na Figura 1, que fizeram o papel de nós difusores de informações. Esses dois produtores possuem um tempo na atividade maior que 10 anos - o que colabora para a troca de informações advindas de seus aprendizados na atividade - e também estão vinculados a órgão de classe (SR) e a instituições públicas de apoio (APTA e SAT), vindo a exercer um nível de posicionamento mais central nessa subrede. O nó 01ES mantém oito laços, sendo um deles com a APTA, instituição pública de apoio; enquanto o nó 05HS mantém dez laços, com um deles vinculas a órgão de classe (SR).

Outras fontes, como literaturas sobre o assunto, palestras e cursos também foram ferramentas auxiliares para que houvesse algum tipo de planejamento.

Para os agentes entrevistados da região de Assis é possível identificar um número bem menor de nós isolados que não formam laços na rede $(12,9 \%)$ - quatro produtores à esquerda do mapa (Figura 2). Esses produtores apontaram não buscar nenhum tipo de informação prévia, devido, primeiramente, ao conhecimento familiar sobre a cultura (conhecimento tácito, passado de geração a geração) e segundo, por terem desconhecimento de órgãos que fornecessem tais informações. 
O grupo de produtores de Assis está envolvido na atividade da mandiocultura há mais tempo que o grupo de Tupã, como já exposto anteriormente (há produtores, inclusive, que estão na atividade há 30/40 anos). Tal fato contribui para a construção de relacionamentos entre eles, o que reduz a possibilidade de agentes desconectados da rede, evitando buracos estruturais. O tempo de relacionamento, em geral, confere atributos de confiança, reforçados pelos processos de reciprocidade, conforme descritos por Granovetter (2007) e Reagans e McEvily (2003).
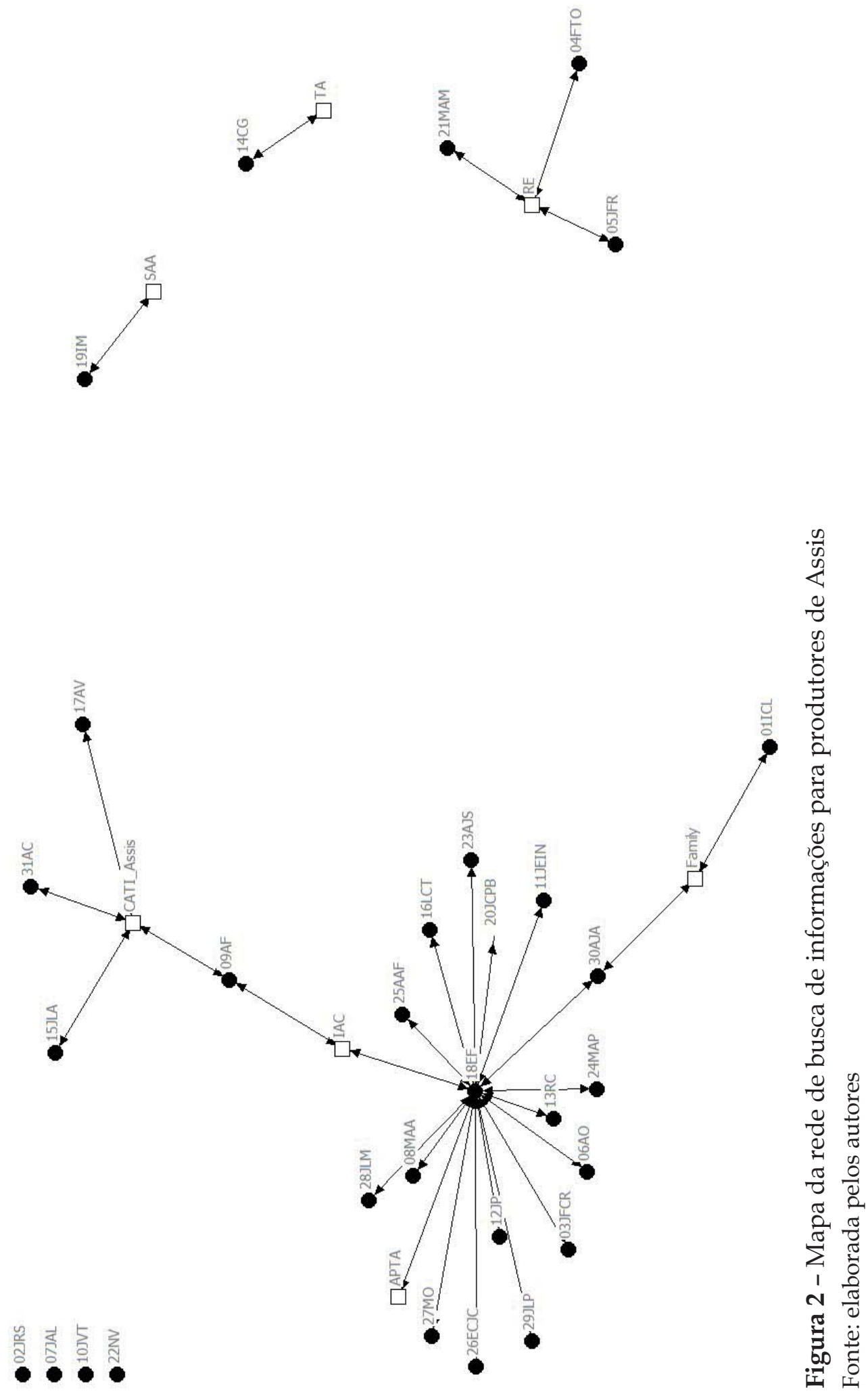

INTERAÇÕES, Campo Grande, v. 16, n. 1, p. 75-86, jan./jun. 2015. 
Para os produtores da amostra de Assis, há sete nós não ligados diretamente à produção, denominados anteriormente como agentes de intermediação de informação. Esses agentes são os seguintes: Secretaria Municipal de Agricultura de Assis (SAA), Coordenadoria de Assistência Técnica Integral - Escritório de Desenvolvimento Rural de Tupã (CATI_Assis), Assistência Técnica Privada (AT), empresas compradoras da região de Assis (ER) ${ }^{12}$, Instituto Agronômico de Campinas (IAC), Agência Paulista de Tecnologia dos Agronegócios (APTA) e familiares (Familia). Pelo papel que cumprem na rede, de acordo com o número de laços que sustentam, poderiam ser assim classificados, conforme sua importância: CATI_Assis, IAC, EC, Familia, APTA, SAA e AT. A ordem exposta diz respeito ao número de laços que seriam eliminados, caso os agentes citados fossem retirados da rede analisada. Importante destacar que $57 \%$ desses são órgãos públicos do estado de São Paulo que possuem a função tanto de gerar e transferir tecnologias, como é o caso da APTA e o IAC (este uma das unidades de pesquisa vinculadas à APTA), como de assistência técnica e treinamento tecnológico (CATI) e assistência técnica, de modo geral (SAA).

Por meio do mapa, pode-se notar três sub-redes que merecem destaque. Uma delas é a representada pela troca de informações, principalmente comerciais, dos agentes produtores (04FTO, 05JFR e 21MAM) com empresas compradoras (EC). Vale destacar que, apesar de somente três agentes $(9,6 \%)$ sinalizarem a troca de informação comercial com as empresas compradoras, de modo qualitativo (não mensurado no mapa), pôde-se notar que, para a maior parte deles, já havia a informação disseminada de 'a quem vender' e de 'preços'. A alta concentração de fecularia ou farinheira na região favorece a absorção e disseminação dessas informações.

A segunda sub-rede é formada por quatro agentes produtores (09AF, 15JLA, 17AV e 31AC) em torno de um órgão público de assistência (CATI_Assis), sendo que um dos produtores também se conecta com instituto de pesquisa (IAC), cumprindo juntamente com o instituto o papel de ponte entre esta

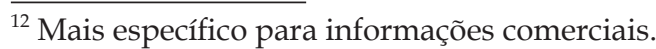

sub-rede e a terceira. Essa sub-rede é desenhada em torno de troca de informações no âmbito produtivo.

A terceira sub-rede a ser destacada é a construída em torno do produtor $18 \mathrm{EF}$, conectando diretamente dezesseis nós $(51,6 \%)$ e três agentes de intermediação, sendo um deles um órgão público de transferência tecnológica (APTA), um instituto de pesquisa (IAC) e membros da família (Familia). A importância desse agente produtor e do número de laços que estabelece é pelo fato de estar integrado verticalmente com a agroindústria, para a transformação da raiz de mandioca em amido de mandioca. Essa sub-rede é utilizada para troca de informações relacionadas principalmente à produção e apresenta relevância pelo número de nós (comparativamente às outras duas sub-redes). Nota-se, portanto, que a motivação desse grupo está nas respostas de 'o que' e 'como' produzir, afetando as decisões acerca dos processos e tecnologias voltadas para a produção.

Observaram-se características diferentes entre as duas regiões analisadas quanto ao grau de maturidade e intensidade de relações. $\mathrm{Na}$ amostra de Tupã, por exemplo, os produtores tendem a se relacionar com agentes de intermediação, prioritariamente agentes públicos, para buscar informação técnicas de produção e gestão da comercialização. Isso é resultante de uma rede difusa (não coesa), de menor senso de proximidade entre os nós e da qual demanda instituições e organizações externas para assegurar a informação e promover confiança. Exceção em torno dos nós 05HS e 01ES de Tupã, que conectam $28 \%$ dos produtores.

Na região de Assis, observa-se ainda um maior nível de laços entre os próprios agentes produtores e também destes com os agentes públicos de pesquisa e de assistência técnica, o que permite inferir sobre a existência de uma rede mais coesa (com menor influência dos buracos estruturais). Alguns produtores são contatados mais frequentemente do que outros (como a sub-rede em torno do produtor 18EF, que conecta $51,6 \%$ dos produtores). Esse número elevado de laços pode ser explicado pela maior reputação e influência desse agente. Isso tende a conduzir para uma maior coesão da rede, ainda que existam hierarquias e polarização de agentes 


\section{Considerações finais}

Com base nos resultados, foi possível verificar a existência de redes sociais que visam à troca de informações acerca do processo produtivo e da comercialização em ambos os municípios analisados. Entretanto os laços estabelecidos visando ao acesso a informações sobre o processo produtivo são mais frequentes e conectam mais nós, sejam eles produtores rurais ou agentes de intermediação, do que informações sobre questões comerciais. Informações acerca de questões comerciais são geralmente obtidas a partir dos laços estabelecidos entre produtores rurais e agentes responsáveis pela compra do produto.

Observou-se que, no município de Assis, a rede social é mais coesa do que aquele encontrada em Tupã. O tempo na atividade da mandiocultura, maior reputação e confiança entre os agentes contribuíram para que os nós, sejam eles produtores rurais ou agentes de intermediação públicos ou privados, estabelecessem um maior número de laços. Esses laços permitiram o acesso e difusão de informações acerca do processo produtivo, principalmente.

Considerando a rede de Tupã, a Secretaria Municipal de Agricultura foi considerada o principal agente difusor de informações acerca do processo produtivo, pois sustentou o maior número de laços. Entretanto destacase que a função dessa instituição é o planejamento das atividades agrícolas do município e não a transferência tecnológica. Essa constatação revela que há uma carência na atuação dos órgãos responsáveis pela difusão e transferência tecnológica, como a Coordenadoria de Assistência Técnica do estado os institutos de pesquisa, instituições presentes nas redes sociais de Assis. Acrescenta-se, ainda, o fato de essa rede possuir nós isolados (nove) que não apontaram laços com outros agentes. Pode-se inferir que o fato de a maior parte desses trabalharem somente com o arrendamento da terra e possuírem menor tempo na atividade conduza a uma menor necessidade de vínculos/ laços por parte desses produtores e reciprocidade de ações.

A rede de Tupã ainda apresenta como característica a presença de dois nós (produtores rurais) que estabelecem um elevado número de laços com outros produtores. Esses, que possuem característica de maior tempo na atividade, servem de pontes para o acesso à informação junto a órgãos públicos.

Apesar das diferenças nas configurações das duas redes estudadas, não há discrepâncias significativas no nível tecnológico de ambas as amostras devido ao fato de ambas adotarem inovações relacionadas com as variedades de mandioca desenvolvidas pelo Instituto Agronômico de Campinas (Instituto de Pesquisa) e possuírem equipamentos e implementos semelhantes. Entretanto há perdas para a rede de Tupã, uma vez que não se beneficiam de informações provenientes de órgãos geradores e difusores da tecnologia, principalmente públicos. Assim, esses produtores perdem a oportunidade de se beneficiar em termos de planejamento da produção, maior produtividadee, consequentemente, maior eficiência produtiva.

Por fim, este trabalho analisou e mapeou as redes sociais envolvendo produtores de mandioca nos municípios de Tupã e Assis quanto à busca de informações acerca do processo produtivo e da comercialização. As conclusões levam a perceber que redes coesas tendem a gerar melhores resultados para a difusão e adoção tecnológica (como no caso da rede de Assis) do que redes difusas (caso da rede de Tupã). Ainda que o acesso às informações seja possível em redes difusas, as redes coesas facilitam a adoção das novas tecnologias, provavelmente, por melhores condições de trocas de informações e experiências entre os nós presentes na rede de Assis. Destaca-se ainda a relevância de instituições voltadas à transferência tecnológica, no caso de Assis, para maior eficiência e competitividade do setor.

A contribuição deste estudo é relevante para a elaboração de políticas públicas que visem promover o acesso e difusão da informação, principalmente para a região de Tupã, cujo número de relacionamentos com órgãos de assistência técnica mais profissionalizada e de pesquisa é menor.

\section{Referências}

AGRIANUAL. Anuário estatístico do Brasil. São Paulo: FNP Consultoria \& Comércio, 2010.

AHUJA, Gautam. Collaboration networks, structural holes, and innovation: a longitudinal study. Administrative Science Quarterly, Michigan, USA, v. 45, n. 3, p. 425-455, Sep. 2000.

AHUJA, Gautam; POLIDORO JR., Francisco; MITCHELL, Will. Structural homophily or social asymmetry? The formation of alliances by poorly embedded firms. 
Strategic Management Journal, Malden, USA, v. 30, n. 9, p. 941-958, 2009.

AHUJA, G.; SODA, Giuseppe; ZAHEER, Akbar. The genesis and dynamic of organizational dynamics. Organization Science, Catonsville, v. 23, n. 2, p. 434-448, 2012.

BARROS, Geraldo Santana C. (Coord.). Melhoria da competitividade da cadeia agroindustrial da mandioca no estado de São Paulo. 1. ed. São Paulo: SEBRAE; Piracicaba, SP: ESALQ/CEPEA, 2004.

BORGATTI, Stephen P.; EVERETT, Martin G.; FREEMAN, L.C. Ucinet for Windows: Software for Social Network Analysis (software). Harvard, MA: Analytic Technologies, 2002.

BURT, Ronald S. The contingent value of social capital. Administrative Science Quarterly, Michigan, USA, v. 42, n. 2, p. 339-365, jun. 1997.

CAMARGO FILHO, Waldemar P. de; ALVES, Humberto S. Produção e mercado de mandioca: análise de preços ao produtor. Informações Econômicas, São Paulo, v. 34, n. 9, set. 2004.

CARDOSO, Carlos Estevão Leite. Competitividade e inovação tecnológica na cadeia agroindustrial de fécula de mandioca no Brasil. 2003. 188p. Tese (Doutorado) - Escola Superior de Agricultura "Luiz de Queiroz", Universidade de São Paulo, 2003a.

CARDOSO, Carlos Estevão Leite; GAMEIRO, Augusto H. Caracterização da cadeia da mandioca no Estado de São Paulo. In: SOCIEDADE BRASILEIRA DE ECONOMIA, ADMINISTRAÇÃO E SOCIOLOGIA RURAL, 41., 2003. Anais... SOBER, 2003.

CEREDA, Marney P. (Coord). Agricultura: tuberosas amiláceas latino americanas. São Paulo: Fundação Cargill, 2002. v. 4.

CRESPO, Joan; REQUIER-DESJARDINS, Denis; VICENTE, Jérôme. Why can collective action fail in local Agri-food system? A social network analysis of cheese producers in Aculco, Mexico. Food Policy, London, v. 46, p. 165-177, 2014.

CROSS, Rob; BORGATTI, Stephen P.; PARKER, Andrew. Making the invisible visible: using social network analysis to support strategic collaboration. California Management Review, Oakland, CA, v. 44, p. 25-46, 2002.

FOOD AND AGRICULTUREORGANIZATION OF THE UNITED NATIONS (FAO). FAOSTAT. Production. 2013. Disponível em URL: <http:/ / faostat3.fao.org/home/ index.html\#DOWNLOAD>. Acesso em: 2 jul. 2013.

FUKUDA, C.; OTSUBO, A. A. Cultivo da mandioca na região centro sul do Brasil. Plantio. 2003. Disponível em: <http:// sistemasdeproducao.cnptia.embrapa.br/ FontesHTML/Mandioca/mandioca_centrosul/plantio. htm>. Acesso em: set. 2011.

GIL, Antonio C. Como elaborar projetos de pesquisa. 4. ed. São Paulo: Atlas, 2002.

GRANOVETTER, Mark. Ação econômica e estrutura social: o problema da imersão. RAE Eletrônica, São Paulo, v. 6, n. 1, Art. 9, jan./jun. 2007.

The strength of weak ties. American Journal of Sociology, Chicago, v. 78, p. 1360-1380, 1973.

HENNEBERG, Stephan C.; SWART, Juani; NAUDÉ, Peter; JIANG, Zhizhong; MOUZAS, Stefanos. Mobilizing ideas in knowledge networks: a social network analysis of the human resource management community 1990-2005. The Learning Organization, v. 16, n. 6, p. 443-459, 2009.

HOWELER, Reinhardt; LUTALADIO, NeBambi; THOMAS, Graeme. Save and grow cassava: a guide to sustainable production intensification. Organização das Nações Unidas para Agricultura e Alimentação (FAO). 2013. Disponível em: <http://www.fao.org/ docrep/018/i3278e/i3278e.pdf>. Acesso em: nov. 2013.

INSTITUTO DE ECONOMIA AGRÍCOLA - IEA. Banco de dados. 2013. Disponível em: <http:/ / ciagri.iea.sp.gov. $\mathrm{br} /$ nia1/subjetiva.aspx?cod_sis=1\&idioma=1>. Acesso em: mar. 2013.

LEVANTAMENTO CENSITÁRIO DAS UNIDADES DE PRODUÇÃO AGROPECUÁRIAS DO ESTADO DE SÃO PAULO - LUPA. 1995/96. Dados consolidados regionais 1995/96. Disponível em: <http://www.cati. sp.gov.br/projetolupa/dadosregionais9596.php> Acesso em: dez. 2012.

2007/08. Dados consolidados regionais 2007/08. Disponível em: <http:/ / www.cati.sp.gov.br/projetolupa/dadosregionais.php> Acesso em: fev. 2011

MARCONI, Maria de A.; LAKATOS, Eva M. Fundamentos de metodologia científica. 5. ed. São Paulo: Atlas, 2003.

MENDES, Judas Tadeu G.; PADILHA, João Batista P. Agronegócio, uma abordagem econômica. São Paulo: Pearson Prentice Hall, 2007.

MERTENS, Frédéric; SAINT-CHARLES, Johanne; MERGLER, Donna. Social communication network analysis of the role of participatory research in the adoption of new fish consumption behaviors. Social Science $\mathcal{E}$ Medicine, Massachusetts, v. 75, p. 643-650, 2012.

REAGANS, Ray; MCEVILY, Bill. Network structure and knowledge transfer: the effects of cohesion and range. Administrative Science Quarterly, Michigan, v. 48, n. 2, p. 240-267, June 2003.

SANTINI, Giuliana A.; OLIVEIRA, Sandra C.;PIGATTO, Gessuir. Análise da relação das variáveis preço e produção da mandioca tipo indústria no estado de São Paulo, 1996 a 2008. Informações Econômicas, São Paulo, v. 40, p. 41-52, 2010.

SCHAEFER, David R.; KORNIENKO, Olga. Building Cohesion in Positively Connected Exchange Networks. Social Psychology Quarterly, Ohio, v. 72, n. 4, p. 384-402, 2009.

SENGHORE, Fatima; CAMPOS-NANEZ, Enrique; FOMIN, Pavel; WASEK, James S. Using social network analysis to investigate the potencial of innovation networks: lessons learned from NASA's international spaces apps challenge. Procedia Computer Science, Harrisburg, v. 28, p. 380-388, 2014.

SIEGEL, David A. Social networks and collective action. American Journal of Political Science, Michigan, v. 53, n. 1, p. 122-138, 2009.

WILLIAMSON, Oliver. Markets and hierarchies: analysis and antitrust implications. New York: The Free Press, 1975.

The mechanisms of governance. New York: Oxford University Press, 1996.

WORRELL, James; WASKO, Molly; JOHNSTON, Allen. Social network analysis in accounting information systems research. International Journal of Accounting Information Systems, Melbourne, v. 14, p. 127-137, 2014. 